\title{
Performance of Additives Concerning Synergistic Effect in Lube Oil
}

\author{
Pramod S. Kathamore, Bhanudas D. Bachchhav, Harijan H. Bagchi
}

\begin{abstract}
Lubricating oils containing ester, gaining more importance due to their friction reducing ability. Screening the performance of lubricating oils prior to field test is of most significance for the new lubricant formulations. In this endeavor, six lubricating blends were formulated having variable concentration of additives (sulfur and ester) in mineral oil and screened for their performance using four-ball tribo-tester. The formulated blends were evaluated for their extreme pressure and anti-wear characteristics as per ASTM standards. Tests were conducted on DUCOM TR- 30L four-ball tester and wear scar diameter were measured on an optical microscope.Compatibility and synergy of additives have been discussed on the basis of various parameters such as anti-wear scar diameter, mean scar diameter (just below weld load), mean scar diameter (at last non-seizure load), weld load and load wear index. The findings of this study demonstrate that ester along-with sulfur not only boost anti-wear properties but also enhance load carrying capacity of oil. An addition of sulfur beyond $2 \%$ may not yield any significant improvement of tribo-characteristics of these oils.This paper is highlighting the synergistic effect of additives to render it as suitable lubricant for metal working applications. This paper also suggested an optimum concentration of an additive for its suitability for anti-wear and/(or) extreme-pressure properties.
\end{abstract}

Index Terms: Anti-wear, Extreme pressure additives, Weld load, Load wear index

\section{INTRODUCTION}

Performance-based rating of mineral oils used in different metal cutting and forming operations assume a lot of significance. In almost every metal cutting operation when lube oil is present, a protective boundary film manages to get developed between the surfaces and carry part of the load resulting in wear resistance of mating surface. Tribological performances of lube oil are very much dependent on its formulation, in particular addition of appropriate additives. The mechanism by which it performs is varied from process to process, material to material, parameters governing the process and also on the integrity of contacting surfaces. Under such conditions, primary screening and evaluation of lube oil in order to study synergistic effect (anti-wear and EP

Revised Manuscript Received on February 05, 2020.

* Correspondence Author

Pramod S. Kathamore*, Research Scholar, Department of Technology, Savitribai Phule Pune University, Pune, Maharashtra, India. Email: kathamorem42pramod@gmail.com

Bhanudas D. Bachchhav, Professor and Head, Department of Mechanical Engineering, All India Shri Shivaji Memorial Society's, College of Engineering, Pune, Maharashtra, India. Corresponding Author Email: bdbachchhav@aissmscoe.com

Harijan H. Bagchi, Professor Emeritus, Department of Production Engineering and Industrial Management, College of Engineering, Pune, Maharashtra, India. Email: hbagchi.prod@coep.ac.in

(c) The Authors. Published by Blue Eyes Intelligence Engineering and Sciences Publication (BEIESP). This is an open access article under the CC BY-NC-ND license (http://creativecommons.org/licenses/by-nc-nd/4.0/) characteristics) of additives prior to field testing needs careful considerations. Anti-wear (AW) and Extreme-Pressure (EP) additives have significantly proved their role in the majority of mineral based as well as vegetable based metalworking processes [1-4, 7-10]. These additives formed a protective layer on the mating surfaces and carry the load.The performance metal forming oils [7-10], cutting fluids [7], deep drawing oils (Bachchhav et al., 2011, 2012, 2014), rolling oils [3-5], wire drawing lubricants [2], engine oils [11-12], have been evaluated using four-ball test tribometer. Recently, a tribological performance of vegetable-based lubricants has been investigated using ball-on-flat reciprocating tribometer [1]. Rheological properties of lubricants do not play any significant role in reducing friction and wear in metalworking processes, however, AW or EP additives have a strong effect on it, helping to reduce wear and ultimately scuffing and seizure of contacting surfaces [4, 15]. The most commonly used EP additives are sulfur, chlorine and phosphorous-based compounds, used either singly or combination of those compounds. Neville, et al.,[13]studied and evaluated synergistic effect of various additives in lube oil and compatibility with lubricant surfaces. Rajendiranet al.,[14]confirmed that substantial reduction in friction and wear can be achieved by blending with esters with minimum or no conventional additives. These additives work by reacting chemically with the interacting surfaces and form a protective tribo-film on them [4, 8-10]. The effect of type of additives and their concentration on lubrication performance need to be addressed for primary evaluation of lubricants, for application in the field. This paper deals with screening the performance of formulated lubricants particularly for their Anti-Wear (AW) and Extreme Pressure (EP) properties following ASTM D2783 and ASTM D4172 standards. Frictional behavior of these lubricants have already been studies in detail by the authors [5]. This primary screening and performance-based rating will narrow down selection of lubricant types to enable the manufacturer or end user to undertake detail characterization of lubricants under a simulative type of test conditions in order to evaluate the suitability of lubricant for a particular metal working process, in relating to tribology.

\section{MATERIALS AND METHODS}

\section{A. Lubricants}

Since sulfur is not desirable additives now-a-days; as an alternate ester is being tried to reduce sulfur content in lubricant. 


\section{Performance of Additives Concerning Synergistic Effect in Lube Oil}

Ester based oil formulation gaining more importance due to their friction reducing ability and inhibit chemically breakdown of ester by forming protective film. The lubricants formulated for this study contain 500 SN (Solvent Neutral) mineral based oil of kinematic viscosity 87.47 cSt. at $40^{\circ} \mathrm{C}$ and a

mixture of Sulfur and Ester. The viscosity of oil plays hardly any role in reducing wear and controlling friction in metalworking processes [4]. Authors intended to evaluate whether the combination of these two additives give synergistic or antagonistic effect and also to study the tribo-effects of additives suitable in metalworking operations, particularly anti-wear property. Lubricant and its properties are given in Table 1.

Table 1 Lubricant Properties

\begin{tabular}{|c|c|c|c|c|}
\hline \multirow[t]{2}{*}{$\begin{array}{l}\text { Lube } \\
\text { Type }\end{array}$} & \multicolumn{2}{|c|}{$\begin{array}{c}\text { Additive } \\
\text { Concentration } \\
\text { (\%by Wt.) }\end{array}$} & \multirow{2}{*}{$\begin{array}{c}\text { Viscosity } \\
\text { cSt. at } \\
40^{0} \mathrm{C}\end{array}$} & \multirow[t]{2}{*}{$\begin{array}{c}\text { Specific } \\
\text { gravity }\end{array}$} \\
\hline & Sulfur & Ester & & \\
\hline Lube A & 1 & 0.75 & 87.50 & 0.864 \\
\hline Lube B & 2 & 0.75 & 88.31 & 0.864 \\
\hline Lube C & 3 & 0.75 & 91.20 & 0.864 \\
\hline Lube D & 2 & 1.50 & 109.77 & 0.88 \\
\hline Lube E & 2 & 3.00 & 114.94 & 0.87 \\
\hline Lube F & 2 & 5.25 & 115.19 & 0.882 \\
\hline Base oil & \multicolumn{2}{|c|}{$\begin{array}{c}\text { SN } 500 \\
\text { mineral oil }\end{array}$} & 87.47 & 0.864 \\
\hline
\end{tabular}

\section{B. Test Balls}

The test balls used were made from AISI standard steel No. E-52100, with diameter 12.7 mm, (Extra Polish grade-25), having Rockwell hardness 64 to 66 Rc. A microscope, equipped with a calibrated measuring scale, was used for scar diameter measurement.

\section{Experimental Method}

The four-ball tester can be used to determine anti-wear properties, load bearing characteristics and friction behavior of lubricants. The test load, duration, temperature and rotational speed are set in accordance with ASTM standards. The average scar diameter on bottom three balls is reported. The size of the scar shows the ability of the lubricant to prevent wear. A larger diameter indicates poor wear preventive property while a smaller indicates superior wear preventive property. In EP tests, the lubricant is subjected to load that is increased in specified steps after every run. This increase in loading is continued till a load is reached where the lubricant fails. The failure of the lubricant is indicated by welding of the bottom three balls to the top ball.

DUCOM, TR-30L, four ball tester has been used for in study. Three steel balls of $12.7 \mathrm{~mm}$ diameter are clamped together in a ball pot assembly and immersed with $50 \mathrm{ml}$ lubricants, which is to be evaluated; a fourth ball of same diameter referred to as the top ball is held in a special collate inside spindle. The top ball is rotated in contact with the three fixed balls, which are immersed in sample oil. Normal load is applied on the balls by loading lever and dead weight placed on the loading pan.

\section{Anti-Wear (AW) performance of lubricants}

Wear tests were performed as per ASTM D-4172 standard. Before starting a series of tests, clamping unit, oil cup and four new balls for each test run were thoroughly cleaned using acetone and wiped with fresh industrial wipe. One of the clean test balls is fixed into the ball chuck. The ball chuck is inserted into the spindle. Three $12.7 \mathrm{~mm}$ diameter steel balls were clamped together and covered with the lubricant to be evaluated. A top ball is pressed with a force $392 \mathrm{~N}$ [40 kgf]. Shock loading was avoided. The temperature of the test lubricant was regulated at $75^{\circ} \mathrm{C}\left[167^{\circ} \mathrm{F}\right]$ and then the top ball was rotated at $1200 \mathrm{rpm}$ for $60 \mathrm{~min}$. The scar diameters both horizontal as well as vertical to the striation marks were measured with an accuracy of $0.001 \mathrm{~mm}$ with the help of an optical microscope.

\section{E. Extreme-Pressure (EP) performance of lubricants}

In order to evaluate lubricant's extreme pressure performance, EP tests were carried out following the ASTM D 2783-88 standard. This test method is different than one which applied for AW test. A series of tests of 10 -sec duration was carried out at increasing loads until seizure occurs. The first run was made an initial load of $618 \mathrm{~N}$ and subsequent runs were carried out at next higher loads, as stipulated in standard i.e. at 785, 981, 1235, 1569, 1961, 2451, 3089, $3922 \mathrm{~N}$ etc. The rotating speed was kept at 1760 rpm with a tolerance of $\pm 60 \mathrm{rpm}$. The wear scar diameter (WSD) in the stationary balls for each run was measured along the striation marks as well as perpendicular to it using an optical microscope of $0.01 \mathrm{~mm}$ accuracy. Before and after each run, test balls, test-lubricant cup and chuck assembly were thoroughly cleaned with acetone and new balls were used for next higher load and test procedure is continued till seizure occurs for each lubricant.

\section{RESULTS AND DISCUSSION}

\section{A. Anti-wear Test Results:}

Lubricants (Lube-A to Lube-F as well as Base Oil) were compared for their wear preventive performance by using the average size of the scar diameter marked on the three lower clamped balls. The observation from topographical images of wear scar shows patchy, continuous or discrete striation markswhere the sliding direction is horizontal. The different colors from green, brown to black, depict an effect of type and concentration of an additive (Fig. 1 ). The color of the film may be due to additive chemistry or surface reaction of the product. However it is very difficult to depict correlation between appearance and topography of the film and effective lubrication regime. The wear scars were optically measured and the repeatability of the values of wear scar diameter was confirmed by conducting three tests for same load.The micrograph of wear scar at $100 \mathrm{X}$ magnification for base oil (Fig. 1g) shows deep worn surface and ragged edges indicating early breakdown of lubricating layer and predominantly adhesive wear in the absence of additives. However; Fig. 1 (a) to 1 (f), in the presence of ester and sulfur, an adsorbed layer protects the surface from wear and shows smooth surfaces with minimum surface damage and smooth edges as compared to (Fig. 1 g) base oil. Lubricant F ( Fig. 1f), shows the drastic reduction of wear scar, smoother and shiny scar surface and hardly any metal transfer indicating non breakdown of film and excellent anti-wear properties when blended with $2 \%$ sulfur and 5.25 $\%$ ester. 
Anti-wear scar diameter (AWSD) based on ASTM D-4172, have been evaluated and shown in Fig. 2. Lubricant F shows lowest AWSD hence having very good AW characteristics (Fig. 2). The values of Anti-wear Scar diameter, Mean Wear Scar Diameter at LNSL (mm) and Mean Wear Scar Diameter at JBWL $(\mathrm{mm})$ are depicted in Table 2.

Table 2 Anti-wear (AW) Test results

\begin{tabular}{llllr}
\hline Lubricant & \multicolumn{2}{l}{$\begin{array}{l}\text { Anti-wear } \\
\text { Scar Dia. } \\
(\mathrm{mm})\end{array}$} & $\begin{array}{l}\text { Mean Wear Scar } \\
\text { Diameter } \\
\text { LNSL } \\
(\mathrm{mm})\end{array}$ & $\begin{array}{l}\text { Mean Wear } \\
\text { Diameter } \\
\text { JBWL } \\
(\mathrm{mm})\end{array}$ \\
\hline Lube A & 0.564 & 0.384 & 2.840 \\
Lube B & 0.520 & 0.490 & 2.564 \\
Lube C & 0.524 & 0.468 & 2.513 \\
Lube D & 0.490 & 0.464 & 2.325 \\
Lube E & 0.472 & 0.450 & 2.760 \\
Lube F & 0.360 & 0.516 & 2.700 \\
Base oil & 0.824 & 0.810 & 2.960 \\
\hline
\end{tabular}

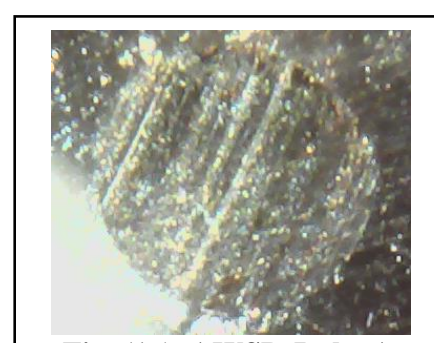

Fig. (1a), AWSD-Lube A
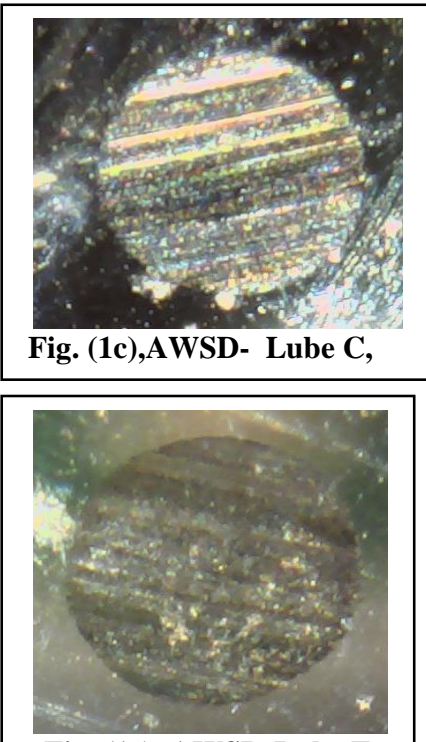

Fig. (1e), AWSD-Lube E

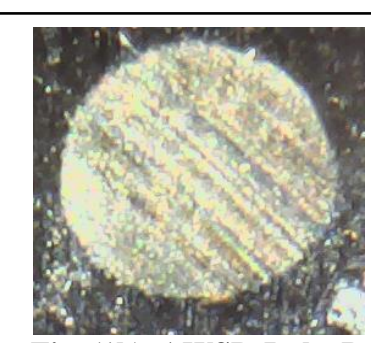

Fig. (1b), AWSD-Lube B
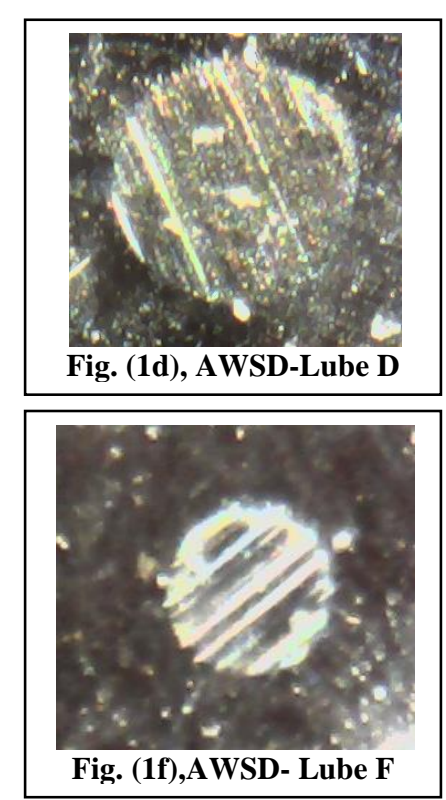

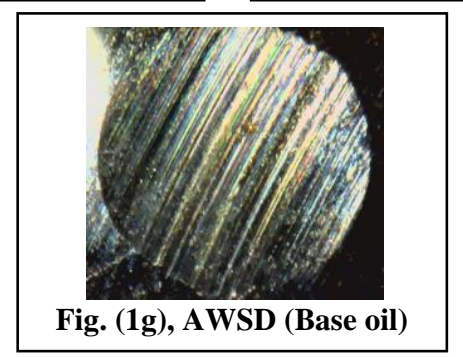

Fig. 1 (a to g) Anti-wear scar diameter at $100 \mathrm{x}$ magnification

\section{B. EP Test Results}

Extreme Pressure (EP) tests have been carried out for Lube A to Lube F as well as for Base oil as per ASTM standards. The extreme pressure test measurements were repeated and averaged out the scar diameter. Following loads were measured.

\section{Last non-seizure Load (LNSL) :-}

The last non-seizure load is the last load at which the measured scar diameter is not higher than $5 \%$ above the compensation line. Usually, the region beyond the Last non-seizure Load (LNSL) is known as extreme pressure (EP) region, whereas the region before the LNSL is the anti-wear (AW) region.

\section{Just Before Weld Load (JBWL):-}

The load just before the weld load (WL) is usually called JBWL.

Weld Load (WL):-

This is the lowest applied load at which the rotating ball seized to the stationary balls.

\section{Load Wear Index (LWI):-}

The load wear index (LWI) is a single parameter that shows the overall EP behavior in a range between well below seizure and welding. It is calculated from the expression:

$$
L W I=\frac{\sum_{i=1}^{n}(L i \times D h . i / D w)}{n}
$$

Where $L_{i}=$ is the applied load, $\mathrm{N}$

$D_{h}=$ is hertz diameter, $\mathrm{mm}$

$D_{w}=$ Avg. wear scar diameter measured on three stationary balls.

$n=$ repetitions

Table 3 Extreme Pressure (EP) Test results

\begin{tabular}{cccc}
\hline Lubricant & $\begin{array}{c}\text { Load Wear } \\
\text { Index,LWI } \\
(\mathrm{N})\end{array}$ & $\begin{array}{c}\text { Last } \\
\text { non-seizure } \\
\text { load LNSL } \\
(\mathrm{N})\end{array}$ & $\begin{array}{c}\text { Weld Load } \\
(\mathrm{N})\end{array}$ \\
\hline Base oil & 149 & 400 & 1569 \\
Lube A & 491 & 618 & 2451 \\
Lube B & 501 & 785 & 3089 \\
Lube C & 544 & 785 & 3089 \\
Lube D & 508 & 785 & 3089 \\
Lube E & 551 & 785 & 3922 \\
Lube F & 683 & 1235 & 3922 \\
\hline
\end{tabular}

Also, Fig. 2 represents Mean WSD at LNSL, Mean WSD at JBWL. Lubricant D shows lowest Mean WSD at LNSL and JBWL. Values of Load Wear Index (N), Last non-seizure load LNSL (N) and Weld load (N) are depicted in Table 3. 


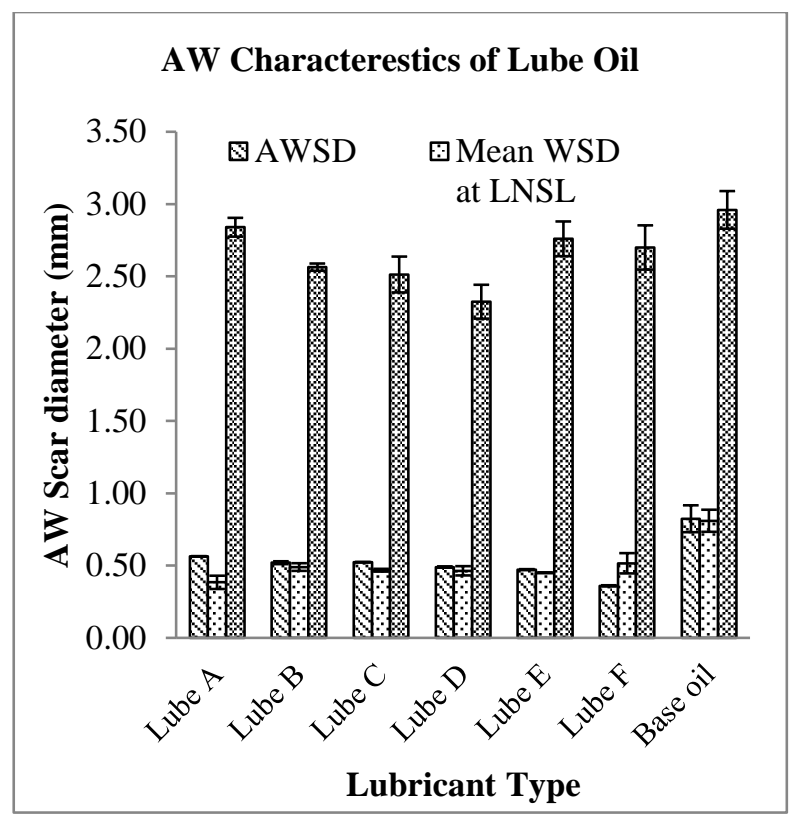

Fig. 2 Anti-wear Characteristics of Lube Oils (ASTM D4172)

Figure 3 depicts Load Wear Index (LWI), Last Non-Seizure Load (LNSL) and Weld Load (WL). Higher the values of these parameters, better the extreme pressure properties of lube oil. From the fig. 3, base oil fails at 1500 $\mathrm{N}$, whereas lubricant $\mathrm{E}$ and $\mathrm{F}$ can bear around $4000 \mathrm{~N}$ load.

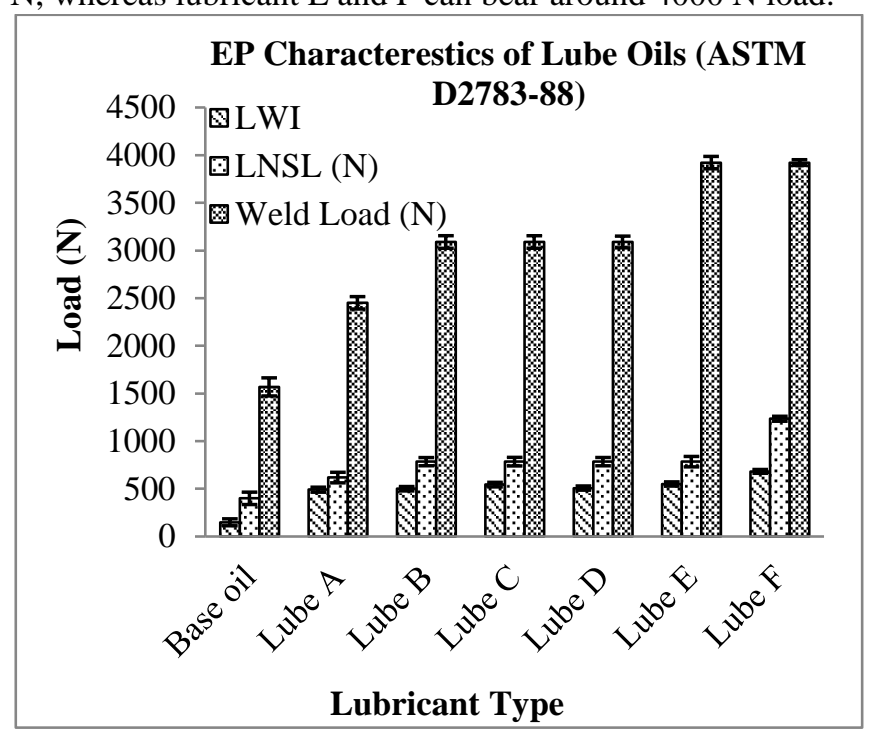

Fig. 3 Extreme-Pressure Characteristics of Lube Oils

Fig. 4 depicts the relationship between the increasing load and variation in the average wear scar diameter with reference to ester concentration (while sulfur concentration is kept at 2\%). In figure 4, each of the curves except for Lube F shows a almost vertical transition from mild to severe wear below $800 \mathrm{~N}$ load. It clearly indicates that increasing ester concentration in oil can bear more load without seizure; Lube F shows lower wear scar diameter (WSD) as compared to others under increasing load.

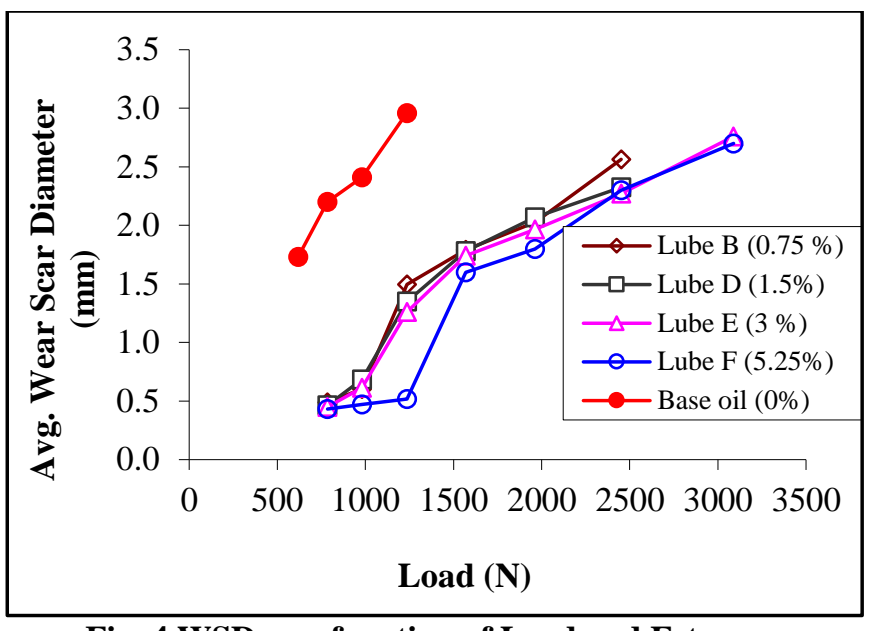

Fig. 4 WSD as a function of Load and Ester Concentration (\%)

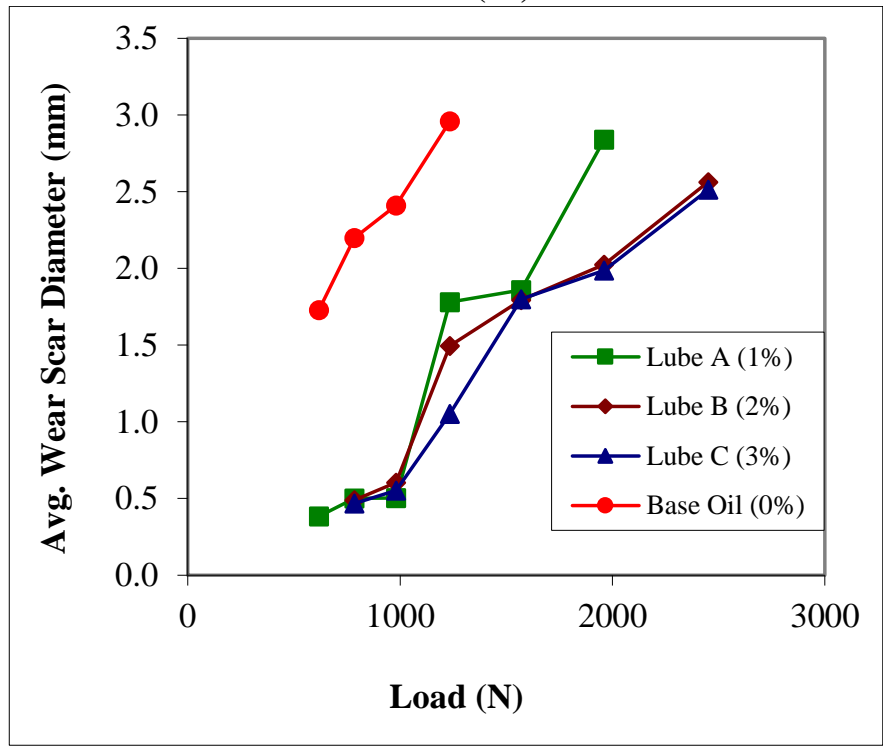

Fig. 5 WSD as a function of Load and Sulfur Concentration

Similarly, Fig. 5 shows an effect of load on WSD at a variable concentration of sulfur, (While ester concentration was kept at $0.75 \%$ ). It has been observed that below $1500 \mathrm{~N}$ load increase in sulfur percentage reduces scar diameter whereas after $1500 \mathrm{~N}$ it does not have significant contribution towards the reduction of WSD. Limiting the value of Sulfur is estimated as $2 \%$.

\section{CONCLUSION}

This study was conducted to investigate the synergistic effect of lubricant containing sulfur and ester particularly on anti-wear and load bearing capacity for sustained lubrication. On the basis of experimental results considering synergistic effect it shows that lube F, which contains $5.25 \%$ of ester, sulfur $2 \%$ has very good anti-wear characteristics.

The results depicts clearly two regions, the region before Last Non-seizure Load (LNSL) as AW which is observed with smaller wear scar diameter; However region after LNSL where scar diameter is much larger. Values of Load Wear Index (LWI), Last Non-seizure Load (LNSL) and Weld Load (WL) depict very good AW and EP characteristics for lube F. 
The study indicates that ester along-with sulfur definitely boosts anti-wear and load carrying capacity. An addition of sulfur beyond $2 \%$ may not prove to be beneficial to improve AW and load bearing capacity.

Study of micrograph showed that the wear scar surface with $2 \%$ sulfur and $5.25 \%$ ester appears to be much smoother and barely any material transfer.The presence of sulfur and ester suggests that both the elements have reacted with substrate to form a mixed film which is responsible for the efficacy of additives under extreme pressure and temperature. This indicates that additives added in appropriate proportion could give desired synergistic effect and reducing wear loss relating the performance of lubricants. However, appropriateness would have to be decided based on the applicability of lubricant in a working scenario.

\section{REFERENCES}

1. Alessandro, R., Roberto D., Massimiliano M., Petr V. and Miroslav M. "Tribological characterization of vegetable lubricants: Comparative experimental investigation on Jatropha curcas L. oil, Rapseed Methyl Ester oil, HydrotreatedRapseed oil”, Tribology International, Vol. 109, pp. 529-540, 2017.

2. Bachchhav, B.D. and Naole, D.R. "Tribo-performance of wire drawing lubricants", Journal of Manufacturing Engineering, Vol. 11, No. 1, pp. 051 -054, 2016.

3. Bachchhav, B.D., Lathkar, G.S. and Bagchi, H., "A study of tribo-characteristics of deep drawing oils", Journal of Manufacturing Engineering, Vol. 6, No. 3, pp. 147-152, 2011.

4. Bachchhav, B.D., Lathkar, G.S. and Bagchi, H., "Tribology of ester added lubricants", Journal of Tribology and Surface Engineering, Vol. 3, No. 1-2, pp. 87-94, 2012.

5. Bachchhav, B.D., Lathkar, G.S. and Bagchi, H., "Frictional characteristics of cold rolling oils", Journal of Tribology and Surface Engineering, Vol. 3, No. 3-4, pp.177-185, 2014.

6. Bachchhav, B.D., Lathkar, G.S. and Bagchi, H., "Tribology of drawing lubricants for low carbon steel", Industrial Lubrication and Tribology,Vol: 66, No. 6, pp. 640-644, 2014.

7. Cambiella, A., Benito, J.M., Pazos, C., Coca, J., Hernandez, A. and Fernandez, J. E., "Formulation of emulsifiable cutting fluids and extreme pressure behavior" Journal of Materials Processing Technology, vol. 184, pp. 139-145, 2007.

8. Canter, N., "Special Report: Trends in extreme pressure additives," Tribology and Lubrication Technology, Vol. 63, No. 9, pp. 10-18, 2007.

9. Canter, N., "Challenges in formulating metal-forming fluids," Tribology and Lubrication Technology, Vol. 65, No. 3, pp. 56-63, 2009.

10. Canter, N., "Special Report: Boundary lubricity additives," Tribology and Lubrication Technology, Vol. 65, No. 9, pp. 10-18, 2009.

11. Gautam Y., Sudhir T. and Jain M., "Tribological analysis of extreme pressure and anti-wear properties of engine lubricating oil using four ball tester", Materials Today: Proceedings", Vol. 5, Issue: 1, pp. 248-253, 2018.

12. Liping W., Hongxing W., Dongya Z., Guangnene D., Xiaohong X. and Youbai X., "Synthesis of a novel borat ester containing a phenylboronic group and its tribological properties as an additive in PAO 6 Base oil", Tribology International, Vol. 121, pp. 21-29, 2018.

13. Neville, A., Morina, A., Haque, T., and Voong, M., "Compatibility between tribological surfaces and lubricant additives-How friction and wear reduction can be controlled by surface/lube synergies", Tribology International, Vol. 40, pp. 1680-1695, 2007.

14. Rajendiran, A., Sumathi A., Krishnasamy K., Kabilan S. and Gangul D., "Antiwear study on petroleum base oils with esters", Tribology International, Vol. 99, pp. 47-56, 2016.

15. Rudnick, L.R., "Lubricant additives, Chemistry and applications", $2^{\text {nd }}$ Edition, CRC Press, 2009.

\section{AUTHORS PROFILE}

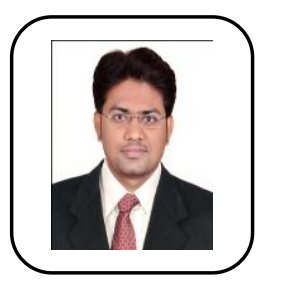

P.S. Kathamoreis pursuing a Ph.D. programme at Department of Technology, Savitribai Phule Pune University. His research interests include advanced manufacturing technology, Optimization techniques and Tribiology. He has four publications in various national and international journals.

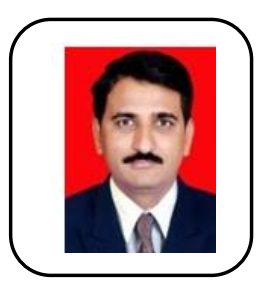

Dr. Bhanudas D. Bachchhav is currently working as a Professor and Head, Department of Mechanical Engineering, All India Shri Shivaji Memorial Society's, College of Engineering, Pune. He is having 18 years of teaching and research experience. He has more than 25 publications in various national and international journals. He has completed three research projects funded by Savitribai Phule Pune University. His area of research is Manufacturing Engineering, Tribology and Metal forming processes.

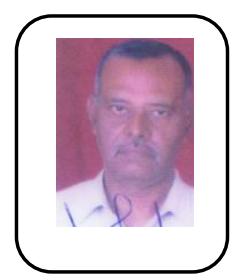

Dr. Harijan H. Bagchi is currently working as a Professor Emeritus atDepartment of Production Engineering and Industrial Management at College of Engineering, Pune. He has 30 years of research experience in the field of design and tribology in one of the national laboratories under Government of India. He has 18 years of teaching experience. 